\title{
Botany
}

\section{Coordination of leaf and stem traits in 25 species of Fagaceae from three biomes of East Asia}

\begin{tabular}{|r|l|}
\hline Journal: & Botany \\
\hline Manuscript ID & cjb-2019-0010.R1 \\
\hline Manuscript Type: & Article \\
\hline Date Submitted by the \\
Author: & 03-Apr-2019 \\
\hline Complete List of Authors: & $\begin{array}{l}\text { Kawai, Kiyosada; Kyoto University, Graduate School of Agriculture } \\
\text { Okada, Naoki; Kyoto University, Graduate School of Global } \\
\text { Environmental Studies }\end{array}$ \\
\hline Keyword: & $\begin{array}{l}\text { functional traits, hydraulic traits, economic spectrum, trait coordination, } \\
\text { vein }\end{array}$ \\
\hline $\begin{array}{r}\text { Is the invited manuscript for } \\
\text { consideration in a Special } \\
\text { Issue? : }\end{array}$ & Not applicable (regular submission) \\
\hline &
\end{tabular}

\section{SCHOLARONE ${ }^{\text {M }}$ Manuscripts}


(i) The full title of the paper

Coordination of leaf and stem traits in 25 species of Fagaceae from three biomes of East Asia

(ii) Authors

Kiyosada Kawai and Naoki Okada

(iii) Affiliation and address

Kiyosada Kawai

Graduate School of Agriculture, Kyoto University, Kyoto 606-8502, Japan

e-mail:k.kawaikx@gmail.com

\section{Naoki Okada}

Graduate School of Global Environmental Studies, Kyoto University, Kyoto 606-8501, Japan e-mail: okad@kais.kyoto-u.ac.jp

(iv)

Name: Kiyosada Kawai

Address: Graduate School of Agriculture, Kyoto University, Kyoto 606-8502, Japan

Telephone: +81 75-753-6096

Fax: +81 75-753-6098

e-mail:k.kawaikx@gmail.com 


\begin{abstract}
It has been debated whether leaf and stem economics spectra are coordinated across species as previous studies provide contradictory results. These studies have been restricted to single biomes, and we hypothesize that climate seasonality may determine the strength of coordination between leaf and stem trait combinations. Herein, using 25 Fagaceae species from East Asia, we investigated the coordination of 15 leaf and four stem traits across and within three biomes (cool temperate, warm temperate, and tropical forests). Traits were chosen to reflect multiple aspects of plant adaptive strategies, such as water, carbon, and nutrient use. The leaf and stem traits of species that reflect resource-use strategies for different resources were functionally coordinated, forming a single axis of trait variation across biomes. This axis represented the trade-off between fast and slow resource-use strategies. We found the trend that the coordination between leaf and stem traits was the strongest in cool temperate forests after removing two Fagus species, followed by warm temperate forests but was not observed in tropical forests. Our results support the proposed model that plants vary from slow to fast resource exploitation, using closely related species, and suggest that temperature modulates the coordination of leaf and stem economics spectra.
\end{abstract}

Key words; functional traits, hydraulic traits, economic spectrum, trait coordination, vein 


\section{Introduction}

One of the goals in plant ecology is to understand the mechanisms generating trait diversity. Different traits are expected to reflect different costs and benefits that influence fitness in a given environment (McGill et al. 2006; Violle et al. 2007). Thus, examining the relationships among traits would clarify the patterns of cost-benefit relationships in plant evolution and give insights into the mechanisms of trait diversification.

Previous studies of cross-species comparisons have revealed the important axes of traits variations that constrain species' life history strategies and distribution. One example is the leaf economics spectrum (LES) (Wright et al. 2004), in which fast resource user are associated with high photosynthetic rate, short leaf lifespan, low leaf dry mass per area (LMA), and high leaf nitrogen and phosphorus concentrations, whereas slow resource user are associated with the opposite suite of traits. LES also underpins the differences in life history strategies across species: fast species achieve high resource acquisition rates and grow rapidly under high resource conditions, whereas slow species use resources conservatively and can persist under low resource conditions (Díaz et al. 2004; Poorter and Bongers 2006; Wright et al. 2010; Sterck et al. 2011).

This fast-slow spectrum for resource-use strategies has been applied to stems as the stem economics spectrum (SES, Chave et al. 2009). In this spectrum, wood density is proposed as a central trait explaining the differences in the resource-use strategies of stems and life history strategies. Species with low wood density are associated with high xylem hydraulic conductivity, low mechanical strength, and low resistance to cavitation, possibly achieving fast growth rates but with low tolerance to shaded and drought conditions, whereas species with high wood density are associated with low hydraulic conductivity but with high mechanical strength and high resistance to cavitation, possibly leading to high stress tolerance but with low growth rates (e.g., Hacke et al. 2001; Jacobsen et al. 2005; Preston et al. 2006; Chave et al. 2009; Wright et al. 2010; Kitajima et al. 2013).

Because leaf and stem are hydraulically and developmentally coupled, it is expected that resource use strategies in leaf and stem are tightly coordinated across species. So far, several studies reported this coordination in different biomes. In subarctic region, leaf and stem traits related to resource capture were highly coordinated in 26 species (Freschet et al. 2010). In a seasonally-dry Mediterranean 
climate, leaf, stem, and root traits were coordinated across 38 species and the strength of the coordination changed among sites with different water availability (de la Riva et al. 2016). In a tropical dry forest, leaf and stem traits related to drought tolerance and construction cost were tightly coordinated across 17 species (Méndez-Alonzo et al. 2012). In the subtropical Bonin Islands, stem wood density was correlated with LMA and leaf-level drought tolerance across 32 angiosperm species (Ishida et al. 2008). By contrast, in a lowland tropical rain forest of French Guiana, LES was decoupled from SES (Baraloto et al. 2010). These results suggest that in harsh or stressful environment with a short growing season leaf and stem traits are coupled whereas in benign environments with a long growing season, they are decoupled. This contrast may be because a longer growing season allows more combinations of leaf and stem traits that achieve similar fitness due to a longer period of time available to compensate for sub-optimal designs. A single analytic framework, however, has not previously been applied in multiple biomes with contrasting temperature-precipitation patterns, limiting our understanding of the extent of the coordination between leaf and stem traits. In this study, using temperature gradient in East Asia, we hypothesized that in the colder region, with a short period favorable for growth, leaf and stem traits would be tightly coordinated across species by strong selection limiting the range of traits (e.g., Weiher and Keddy 1995; Cornwell and Ackerly 2009), whereas warmer regions would allow different combinations of traits in leaf and stem. By exploring the role of climate on the patterns of organ coordination in higher plants, we will gain insights on the ecological and evolutionary forces that determine the diversification of structure and function globally.

Herein, we extended previous research by 1) incorporating leaf and stem traits that reflect water-use strategies, 2) testing the evolutionary robustness of the coordination between leaf and stem by using closely related species, and 3) testing differences in trait coordination among multiple biomes. For the first point, most previous studies examined easily-measurable traits reflecting carbon and nutrient-use strategies (e.g., leaf nitrogen concentration and wood density) to define species' resource use strategies along the economics spectrum (e.g., Wright et al. 2004; Baraloto et al. 2010; Díaz et al. 2015; de la Riva et al. 2016). On the other hand, plant water use strategies (e.g., hydraulic efficiency and drought tolerance) have been less frequently measured, especially at the community scale (GriffinNolan et al. 2018) despite their importance in determining plant adaptive strategies. In particular, hydraulic conductance in organs is a determinant of photosynthetic rate (Santiago et al. 2004; Brodribb 
et al. 2007; Sack et al. 2013), relative growth rate (Poorter et al., 2010), and tolerance to shade and drought (Markesteijn et al. 2011) across a wide range of plant species. Herein, we considered minor vein density and vessel anatomy as proxies for hydraulic efficiency in leaves and stems, respectively (Tyree and Zimmermann 2002; Kawai and Okada 2016; Scoffoni et al. 2016) and examined their relationships with LES and SES.

For the second point, most previous studies examined the relationships between leaf and stem traits using species with different evolutionary histories (e.g., Freschet et al. 2010; Méndez-Alonzo et al. 2012). Therefore, trait relationships have not been confirmed among closely related species in a phylogenetic context. Herein, we investigated Fagaceae, an ecologically and economically important group in the Northern Hemisphere, which shows diverse leaf and stem traits across species (CavenderBares et al. 2004; Kawai and Okada 2016; Aguilar-Romero et al. 2017).

For the third point, to our knowledge, there are few studies to examine the coordination between leaf and stem traits in different biomes. Because Fagaceae dominates in wide range of biomes in Northern Hemisphere, the family is appropriate to test the trait coordination while limiting phylogenic differences.

Our study aims to examine, using 25 Fagaceae species from East Asia, (1) whether the leaf and stem traits that represent resource-use strategies concerning carbon, water, and nutrient are functionally coordinated and (2) how this coordination changes among three biomes (cool temperate forest, warm temperate forest, and tropical forest). We hypothesized that in the colder region, with a short period favorable for growth, leaf and stem traits would be tightly coordinated across species by strong selection limiting the range of traits, whereas warmer regions would allow different combinations of traits in leaf and stem.

\section{Materials and methods}

\section{Plant species and habitats}

We studied 25 Fagaceae species varying in leaf and stem traits sampled from seven forest sites in Japan and one in Thailand (Table 1, for detail of the site information, see Supplementary data, Table $\mathrm{S} 1^{1}$ ). We

\footnotetext{
${ }^{1}$ Supplementary data are available with the article through the journal Web site
} 
classified each site to three biomes (cool temperate, warm temperate, and tropical forests, including subtropical forest) based on the mean annual temperature (MAT) and dominant forest type. In Japan, deciduous species are highly dominant in a cool temperate forest, and their abundance peaks around $9^{\circ} \mathrm{C}$ in MAT, whereas evergreen species increase their abundance starting around $10^{\circ} \mathrm{C}$ in MAT (Aiba et al. 2016). Therefore, we defined cool temperate, and warm temperate, and tropical forests as forests with MAT $<12^{\circ} \mathrm{C}$, from $12^{\circ} \mathrm{C}$ to $20^{\circ} \mathrm{C}$, and $>20^{\circ} \mathrm{C}$, respectively (Table S1). We used temperature for classification of biomes because all study sites receive relatively high precipitation (aridity index, defined as the mean annual precipitation divided by the mean annual evapotranspiration, was above 1.4, see Table S1 for detail) and because temperature mainly determines species' distribution and forest types in East Asia (e.g., Kira 1977; Kubota et al. 2014). Our study site covered a latitudinal range from $14.48^{\circ} \mathrm{N}$ to $43.25^{\circ} \mathrm{N}$, mean annual temperature range from $4.6^{\circ} \mathrm{C}$ to $26.3^{\circ} \mathrm{C}$, and mean annual precipitation from 846 to $2843 \mathrm{~mm}$. The number of Fagaceae species sampled was 10, 14, and eight from cool temperate, warm temperate, and tropical forests, respectively. Six species occurred in two biomes (Table 1, Supplementary data, Table S2). Approximate number of Fagaceae in each site is shown in Table S1. Collection of leaves and stem cores were carried out from June to November 2016. A total of 15 leaf and four stem traits were measured in this study (Table 2).

\section{Measurement of leaf traits}

We collected at least 10 fully expanded, sun-exposed leaves at a height of 3-11 m from one to six mature trees (mean 4.6 $\pm 1.4 \mathrm{SD}$ ) per species and biome. Most trees sampled were between $10-40 \mathrm{~cm}$ in DBH (diameter at breast height) and between 7-18 $\mathrm{m}$ in height. Samples were immediately enclosed in plastic bags and transported to the laboratories for further analyses. Some leaves were chemically fixed with c. $3 \% \mathrm{w} / \mathrm{w}$ glutaraldehyde for the observation of the stomata and veins.

Lamina thickness (LT: $\mathrm{mm}$ ) was measured at the middle point of the leaf lamina for 10 leaves per tree, avoiding the primary and secondary veins, using a micrometer (MDC-25MX, Mitutoyo, Kanagawa, Japan). We then scanned the same leaves using a flat-bed scanner (Epson, Nagano, Japan) at $600 \mathrm{dpi}$. Leaves were subsequently oven-dried $\left(65^{\circ} \mathrm{C},>72 \mathrm{~h}\right)$ and weighed. Individual leaf area (LA: $\mathrm{cm}^{2}$ ) was calculated using the scanned images, using Fiji (Schindelin et al. 2012). Leaf dry mass per area (LMA: $\mathrm{g} \mathrm{m}^{-2}$ ) was calculated as total leaf dry mass divided by leaf area. Lamina tissue density (TD: 
$\mathrm{g} \mathrm{cm}^{-3}$ ) was calculated as LMA divided by lamina thickness. We included the petiole in the calculation of LA and LMA.

To determine lamina mechanical strength, we carried out a punch test. We tested at the middle point of the leaf lamina for at least 10 leaves per tree, avoiding the primary and secondary veins, using a flat-ended cylindrical steel punch ( $2 \mathrm{~mm}$ in diameter) attached with a digital force gauge (DS250N, IMADA, Toyohashi, Japan) and a steel die with a small hole (2.1 $\mathrm{mm}$ in diameter). We standardized the force to punch (unit: N) in three ways. Firstly, we calculated force to punch per unit perimeter of fracture $\left(F_{\mathrm{p}}: \mathrm{kN} \mathrm{m}^{-1}\right)$ and obtained force to punch per unit fracture surface area (or specific force to punch, $F_{\mathrm{ps}}: \mathrm{MN} \mathrm{m}^{-2}$ ) by dividing $F_{\mathrm{p}}$ by lamina thickness (LT). Secondly, density-corrected specific force to punch $\left(F_{\mathrm{TD}}: \mathrm{N} \mathrm{g}^{-1} \mathrm{~m}\right)$ was obtained by dividing $F_{\mathrm{ps}}$ by lamina tissue density (TD). The latter two are classified as material strength, which do not depend on the size or morphology of the leaf, whereas $F_{\mathrm{p}}$ is classified as structural strength, which reflects the size or morphology of the leaf as well as its material strength (Westbrook et al. 2011). We used $F_{\mathrm{TD}}$ as a correlate of leaf cellulose per unit leaf mass (Kitajima et al. 2012).

To evaluate leaf gas exchange capacity, we measured stomatal density (SD: $\mathrm{mm}^{-2}$ ) and calculated potential maximum stomatal conductance to water vapor $\left(g_{\text {smax }}: \mathrm{mol} \mathrm{m}^{-2} \mathrm{~s}^{-1}\right)$. A replica of the abaxial surface of one leaf per tree was obtained by Suzuki's Universal Micro-Printing method (KENIS LIMITED, Osaka, Japan). In pubescent leaves, trichomes were gently removed by duct tape and a razor blade. The images were captured with a digital camera (EOS kiss X3, Canon, Tokyo, Japan) coupled to a light microscope (BX50, Olympus, Tokyo, Japan). Stomatal images were captured at two different resolutions; 1919 and 7679 pixels per $\mathrm{mm}$ with a full extent of $1.3 \mathrm{~mm} \times 0.8 \mathrm{~mm}$ and $0.3 \mathrm{~mm} \times 0.2 \mathrm{~mm}$ for the calculation of SD and $g_{\text {smax }}$, respectively. The number of stomata was manually counted in at least three different views (c. $0.24 \mathrm{~mm}^{2}$ each) using Fiji. The $g_{\text {smax }}$ was estimated by equation 1 (Franks and Farquhar 2001), which is as follows:

(Eqn1)

$$
g_{\text {smax }}=\frac{d}{v} \mathrm{SD} \frac{a}{l+\frac{\pi}{2} \sqrt{a / \pi}}
$$


where $d$ is the diffusivity of water in air at $20^{\circ} \mathrm{C}\left(2.42 \times 10^{-5} \mathrm{~m}^{2} \mathrm{~s}^{-1}\right) ; v$ is the molar volume of air at $20^{\circ} \mathrm{C}\left(0.024 \mathrm{~m}^{3} \mathrm{~mol}^{-1}\right) ; \mathrm{SD}$ is the stomatal density $\left(\mathrm{m}^{-2}\right) ; a$ is the maximum pore area $\left(\mathrm{m}^{2}\right)$; and $l$ is the pore depth $(\mathrm{m})$. The mean guard cell width was substituted for pore depth $(l)$ based on the assumption that guard cells are approximately circular in cross section. Maximum pore area $(a)$ was calculated from the guard cell length, assuming that a stomatal pore is a circle (Brodribb et al. 2013) We measured at least 20 stomata for the calculation of $a$ and $l$ and averaged values were used.

To evaluate leaf hydraulic efficiency, we measured minor vein density $\left(\mathrm{VLA}_{\min }: \mathrm{mm} \mathrm{mm}^{-2}\right)$. For one leaf per tree, we cut a small section $\left(\mathrm{c} .1 .5 \times 1.5 \mathrm{~cm}^{2}\right)$ from the middle of the lamina and immersed it in $5 \% \mathrm{w} / \mathrm{v} \mathrm{NaOH}(\mathrm{aq})$ until it became transparent. Then, the section was rinsed with tap water and stained with $1.0 \% \mathrm{w} / \mathrm{v}$ safranin (in $50 \%$ ethanol). After being rinsed with ethanol, images were captured with a digital camera (EOS kiss X3, Canon) coupled to a light microscope (BX50, Olympus). The resolution of the images was 763 pixels per mm with a full extent of $3 \mathrm{~mm} \times 2 \mathrm{~mm}$. The length of the minor vein ( $>3 \mathrm{rd}$ order vein) was calculated by manually tracing the veins in a c. $2 \mathrm{~mm}^{2}$ region, using Fiji. The minor vein density was calculated as the minor vein length divided by the area of the analyzed region. The minor vein thickness (VT: $\mathrm{mm}$ ) was calculated by averaging the thickness of each order vein measured at one point. The minor vein volume per unit area (VVA: $\mathrm{mm}^{3} \mathrm{~cm}^{-2}$ ), an index of the construction cost of minor veins, was calculated as $\pi(\mathrm{VT} / 2)^{2} \times \mathrm{VLA}_{\min }$.

We also measured lamina $\delta^{13} \mathrm{C}$ (unit: \%o), an indicator of long term water use efficiency (Farquhar et al. 1989). The same leaves used for the calculation of LMA were ground with a mill. $\delta^{13} \mathrm{C}$ was measured using an isotope-ratio mass spectrometer (DELTA V Advantage, Thermo Fisher Scientific, Massachusetts, USA) at the Center for Ecological Research (CER), Kyoto University. At the same time, dry mass-based nitrogen concentration $\left(N_{\text {mass }}: \%\right)$ was measured using a coupled elemental analyzer (Flash 2000, Thermo Fisher Scientific). Area-based leaf nitrogen concentration $\left(N_{\text {area }}: \mathrm{g} \mathrm{m}^{-2}\right)$ was obtained by multiplying $N_{\text {mass }}$ by LMA. We used both area- and mass- based expressions which represent investment of nitrogen per unit area and per unit leaf dry mass investment, respectively, to examine how these variables are related to resource use strategies in leaf and stem. 
We collected one stem wood core (3-4 cm in length) with an increment borer $(5.15 \mathrm{~mm}$ in diameter, Haglöf, Långsele, Sweden) at breast height of five to eight trees per species and biome, including tress from which we sampled leaves. The fresh volume was determined by measuring the diameter and length of a core, assuming a cylindrical shape. The samples were then oven-dried $\left(65^{\circ} \mathrm{C},>72 \mathrm{~h}\right)$ and weighed. Wood density (WD: $\mathrm{g} \mathrm{cm}^{-3}$ ) was calculated as the dry weight divided by the fresh volume.

We quantified vessel anatomy with the same sample for three trees per species and biome. After being rehydrated in tap water for overnight, transverse sections approximately $20-30 \mu \mathrm{m}$ thick were prepared with a sliding microtome. Samples were double-stained with $1.0 \% \mathrm{w} / \mathrm{v}$ safranin (in $50 \%$ ethanol) and $1.0 \% \mathrm{w} / \mathrm{v}$ fast green (in 95\% ethanol) and dehydrated through an ethanol series (50\%, $95 \%$, and $100 \%$ ). Finally, samples were dehydrated in xylene and mounted on a glass slide with Canada balsam. Images were captured using a digital camera (EOS kiss X3, Canon) coupled to a stereoscopic microscope (SZX-12, Olympus). The resolution of images was 789 pixels per mm with a full extent of c. $6 \mathrm{~mm} \times 4 \mathrm{~mm}$. Images were binarized using GIMP ver. 2.8.18 (GNU Image Manipulation Program; available on www.gimp.org) and a rectangle-shaped region $\left(10-23 \mathrm{~mm}^{2}\right)$ was set on each image for analysis of xylem anatomy. Vessel density (VD: $\mathrm{mm}^{-2}$ ) was defined as the number of vessels divided by the area of the analyzed region. Mean hydraulically weighted diameter $\left(D_{\mathrm{h}}: \mathrm{mm}\right)$ was calculated using equation 2 (Tyree and Zimmermann 2002), which is as follows:

$$
D_{h}=\sqrt[\frac{1}{4}]{\frac{1}{n} \sum_{i=1}^{n} d^{4}}
$$

where $d$ is the diameter of each vessel. Since a vessel cross section is not exactly a circle, $d$ was calculated as the average of the mean lengths of the major and minor axes of ellipses fitted to each vessel. Using VD and $D_{\mathrm{h}}$, we calculated the potential specific hydraulic conductivity $\left(K_{\mathrm{h}}: \mathrm{kg} \mathrm{m}^{-1} \mathrm{MPa}^{-1}\right.$ $\mathrm{s}^{-1}$ ) using equation 3 (Poorter et al., 2010), which is as follows:

(Eqn3)

$$
K_{\mathrm{h}}=\frac{\pi \rho_{w}}{128 \eta} \operatorname{VD} D_{h}^{4}
$$


where $\rho_{\mathrm{w}}$ is the density of water at $20^{\circ} \mathrm{C}\left(998.2 \mathrm{~kg} \mathrm{~m}^{-3}\right) ; \eta$ is the viscosity of water at $20^{\circ} \mathrm{C}(1.002 \times$ $10^{-3} \mathrm{~Pa} \mathrm{~s}$ ). Note that $K_{\mathrm{h}}$ is higher than the measured conductivity since $K_{\mathrm{h}}$ does not consider the flow resistance through intervessel pits, which typically accounts for $>50 \%$ of the total resistance of the vessel network (Wheeler et al. 2005; Choat et al. 2008) and embolized vessels. Since pore zones (earlywood containing relatively large vessels) accounted for $>90 \%$ of $K_{\mathrm{h}}$ in ring-porous species (deciduous Quercus and Castanopsis sieboldii, Table S2), we reported VD, $D_{\mathrm{h}}$, and $K_{\mathrm{h}}$ on pore zones for these species. Olson et al. (2014) showed that intraspecific variation in vessel traits is largely driven by tree size, but we considered that, at least for our studied species, variation in vessel traits is driven by other factors (e.g., environment), because neither DBH nor height were correlated to vessel traits across species $(r=0.03-0.27, P>0.20)$.

\section{Statistical analyses}

All analyses were carried out in R (ver. 3.3.2; R core team, 2016). We calculated the mean trait values for each species in each biome and some trait values were $\log _{10}$-transformed before analyses to improve normality and heteroscedasticity (Table 2; Table S2). Firstly, we examined the relationships among traits by generating the correlation matrix for all of the variables using the Pearson correlation coefficient $(r)$. Then, to summarize the relationships, we performed two principal component analyses (PCA); the first PCA included leaf and stem traits (global PCA) and the second PCA included either leaf or stem traits (individual PCAs). We conducted the above PCA analyses for both across and within biomes. In the global PCA across biomes, we averaged the trait values of species, which occurred in multiple biomes. Finally, to assess the degree of coordination between leaf and stem traits, we used the Pearson correlation coefficient between the species' scores of the first and second component of individual PCAs which included either leaf and stem traits. In above PCAs, we also included species' evergreenness $($ deciduous $=0$, evergreen $=1$, Table S2) and vessel porosity in stem (ring-porous $=1$, diffuse-porous $=0$, Table S2) to examine whether these characteristics are linked to species' resource use strategies. We did not conduct phylogenetic analyses because at present a well-resolved phylogenetic tree is not available for our species.

\section{Results}




\section{Overall patterns of relationships between leaf and stem traits}

The 25 species of Fagaceae of this study exhibited a broad range of variation in leaf and stem traits (Table 2; Table S2). Many leaf and stem traits were significantly correlated (Fig. 1; Table 3). Overall, $F_{\mathrm{ps}}, F_{\mathrm{TD}}, g_{\mathrm{smax}}, \mathrm{SD}, N_{\text {mass }}$, and LA were the leaf traits that strongly correlated with stem traits. Hydraulic traits were positively correlated between leaves and stems (e.g., $g_{\text {smax }}$ and $K_{\mathrm{h}}$; Fig. 1a) and among leaves (e.g., SD and $\mathrm{VLA}_{\min }$ ), whereas several traits could be automatically related (e.g., SD and $g_{\text {smax }}$ because $g_{\text {smax }}$ was estimated from SD).

The first axis in the global PCA across biomes accounted for $36.77 \%$ of the variance of 21 traits with positive loadings of leaf and stem structural properties (evergreenness, $F_{\mathrm{p}}, F_{\mathrm{ps}}, F_{\mathrm{TD}}, \mathrm{VT}, \mathrm{VVA}$, LT, LMA, and WD; Fig. 2a, Table 2) and area-based leaf nitrogen content ( $\left.N_{\text {area }}\right)$ and with negative loadings of leaf and stem hydraulic traits $\left(g_{\text {smax }}, \mathrm{SD}, \mathrm{VLA}_{\min }\right.$, vessel porosity, $D_{\mathrm{h}}$, and $\left.K_{\mathrm{h}}\right)$, mass-based leaf nitrogen content $\left(N_{\text {mass }}\right)$, and LA. The second axis explained $18.34 \%$ of the variance with positive loadings of VD and negative loading of hydraulic and structural traits in leaf and stem $\left(g_{\text {smax }}, \delta^{13} \mathrm{C}, N_{\text {area }}\right.$, LT, LMA, vessel porosity, $D_{\mathrm{h}}$, and $K_{\mathrm{h}}$ ).

The global PCA indicated that most leaf and stem traits vary along a single axis (Fig 2a; Table 2), along which one end was characterized by species with an efficient leaf and stem transport systems, high gas exchange capacity, and low leaf and stem construction cost associated with low mechanical strength (fast resource use). The opposite end was characterized by species with mechanically tough leaves and stems with high construction cost and by low photosynthetic capacity and low hydraulic efficiency of leaves and stems (slow resource use). Species' scores in PC1 of the global PCA (Fig. S1) did not differ among genera (one-way ANOVA, $P=0.20$ ) but those in PC2 was greater for Fagus than other four genera (one-way ANOVA, $P<0.001$; Tukey's test, $P<0.05$ ) due to their high VD (Table S2). Consistently with loading of evergreenness, we found that deciduous species had lower values in PC1 than evergreen species (t-test, $P<0.001)$ but that values of PC2 was not significantly different between evergreen and deciduous species.

Individual PCAs including either leaf or stem traits explained $55.16 \%$ and $87.82 \%$ of the variances in the first two axes, respectively (Supplementary data, Figs. S2a, b). They showed qualitatively similar patterns to the global PCA. The PC1 scores in the stem PCA and leaf PCA were positively correlated across 25 Fagaceae species $(r=0.55, P=0.004$, Fig. $2 b)$. Excluding two species 
of Fagus, which showed slightly higher PC1 scores than others in the stem PCA (Fig. 2b), increased the strength of the correlation $(r=0.71, P<0.001)$.

\section{Patterns of relationships between leaf and stem traits in the three biomes}

The PCAs for each of the three biomes (cool temperate, warm temperate, and tropical forests) showed generally similar patterns to the PCA across the three biomes (Figs. 2a, c, e, and g) although the loadings of traits for PC1 were the opposite in the warm temperate forest. This similarity was also observed for the PCAs including either leaf or stem traits (Fig. S2). The species' PC1 scores in leaf and stem PCA were significantly correlated in the warm temperate forest but not in the cool temperate and tropical forests (Figs. 2d, f, and h). Removing two outliers (Fagus crenata and Fagus japonica) with high scores of the stem PC1, however, made the relationships highly significant at the cool temperate forest (Fig. $2 \mathrm{~d})$.

\section{Discussion}

Using 25 Fagaceae species with strong differentiations in leaf and stem traits, we observed tight coordination in the resource-use strategies between leaf and stem. The principle novel findings were that, 1) in resource-use strategies of species for carbon, water, and nutrient, leaves and stems were functionally coordinated, forming a single axis of trait variation and that 2) the strength of this coordination changed among biomes.

\section{Coordination between leaf and stem traits}

We demonstrated that leaf and stem traits that reflect resource-use strategies in carbon, water, and nutrient were functionally integrated into a single axis of trait variation in 25 Fagaceae (Table 2; Figs. 1, 2a, b). These results support the life history theory that leaf and stem traits are coordinated irrespective of resources such that a single axis of trait variation explains most woody plant strategies along the trade-off between fast and slow resource-use strategies (Grime et al. 1997; Méndez-Alonzo et al. 2012; Reich 2014) Along this spectrum, one extreme is characterized by cheap leaves and stems, high water supply capacity, and high photosynthetic rate, possibly associated with high growth rates (e.g., Poorter and Bongers 2006; Fan et al. 2012), whereas the opposite extreme is characterized by tough leaves and 
stems, low photosynthetic capacity, possibly associated with low mortality (e.g., Wright et al. 2010; Kitajima et al. 2013). In the present study, deciduous species were generally fast resource user, whereas evergreen species were slow resource user. Our results also provided evidence of evolutionary robustness in frequently-reported relationships in water use strategies, including the positive relationships between stem hydraulic conductance and gas exchange capacity (Brodribb and Feild 2000; Santiago et al. 2004; Meinzer et al. 2008; Zhang and Cao 2009) and between liquid and gaseous phase conductance in leaves (Sack et al. 2003; Boyce et al. 2009), both of which have been reported in species with different evolutionary histories.

As novel relationships, we found that minor vein thickness (VT) and minor vein volume per area (VAA) were positively correlated with LT and LMA (Table 3). There are two possible explanations for this. Firstly, since veins are made of cellulose-rich material with high tissue density (Villar et al. 2009), their abundance may positively influence leaf construction cost (LMA) via an increase in VAA. Secondly, the thickness of minor veins is mainly accounted for by the thickness of bundle sheath cells, which scales with lamina thickness across species (John et al. 2013) due to developmental constraints (Pantin et al. 2012). Thus, developmental coordination between leaf tissues and organs could cause the positive relationship observed between VT and LT. This relationship may further cause the positive relationship of VT with LMA since LMA was determined by LT and not by TD in the present study $(\mathrm{LMA}=\mathrm{LT} \times \mathrm{TD}$; Table 3$)$. The weaker association of LMA with VVA than with VT (Table 3), however, seems to support the latter explanation. On the other hand, VT was positively correlated with $F_{\mathrm{ps}}$ and $F_{\mathrm{TD}}$ which were independent from LT or LMA (Table 3). This suggests that diameter of minor veins directly affects lamina mechanical strength and may affect leaf lifespan (e.g., Kitajima et al. 2012) irrespective of leaf structural properties. Future studies should evaluate the contribution of VT to leaf strength in Fagaceae by examining the degree of reinforcement of minor veins by sclerenchyma or collenchyma and by considering possibly co-varying anatomical traits outside minor veins (e.g., sclereids).

We also found that leaf area was positively correlated with $g_{\text {smax }}, D_{\mathrm{h}}$, and $K_{\mathrm{h}}$ (Table 3) and was involved in the trade-off between fast-slow resource use strategies (Fig. 2a, Table 2). Because larger leaf area enhances light interception per leaf, leaf area would be functionally coordinated with traits related to other recourse use (e.g., water). The positive relationship between LA and $K_{\mathrm{h}}$ indicates 
the balance between water-transpiring surface area and capacity of water conduction, given the limited variation of leaf area: sapwood area at shoot level among species (K. Kawai \& N. Okada unpublished data).

\section{Influence of climate on stem and leaf relationships}

Consistent with our hypothesis, the strongest relationship between leaf and stem was observed in the cool temperate forest (except two Fagus species) with short growth-favorable period, followed by the warm temperate forest, and tropical forests (Fig. 2). This trend is generally consistent with the compilation of previous studies (Ishida et al. 2008; Baraloto et al. 2010; Freschet et al. 2010) conducted in different regions and with different species. However, because of the lower number of species examined at each biome, this result should be seen as a trend. Moreover, even in cool and warm temperate forests, the coordination between leaf and stem PCA was largely brought by the contrasting resource-use strategies between deciduous and evergreen species (Figs. 2d, f). Therefore, at least in Fagaceae, the change in the composition of deciduous and evergreen species along climatic gradient may partially influence the strength of coordination between leaf and stem traits.

Decoupling of leaf and stem traits in tropical species (Fig. 2h) may be related to low variation in stem traits, especially in vessel traits but to comparable variation in leaf traits (Supplementary data Table S3). In addition, the lowest strength of coordination in the tropical forest mirrored the low variance explained by the PC1 in both the global and individual PCAs (Figs. 2g and S2g). This suggests the presence of other axes of trait variation in tropical forests apart from the trade-off between slow and fast resource-use strategies, probably due to more niches available in tropical forests than in temperate ones. The removal of two Fagus species in the cool temperate forest (Fig. 2d) may be justified to some degree because Fagus is located in a distant clade in the evolution of Fagaceae (Manos and Stanford 2001; Kamiya et al. 2003) and because they exhibit distinct vessel anatomy (denser vessels with smaller diameters than others, Table S2). Nevertheless, this result highlights that the relationship among leaf and stem traits are to some degree dependent on the evolutionary histories of the species concerned, as shown in LES (Heberling and Fridley 2012).

Since our study sites generally receive high precipitation (Table S1), difference in temperature or associated length of growth-favorable period (e.g., Kikuzawa et al. 2013) may be related 
to the observed change in the coordination between leaf and stem traits among biomes, as in LES (e.g., Wright et al. 2005; Funk and Cornwell 2013). Our observation suggests that warm and humid regions with long growth-favorable period can accommodate larger number of combinations of leaf and stem traits apart from the trade-off between slow and fast resource-use strategies. This is consistent with the observation of greater ranges in trait variation in tropical forests than in temperate forests (e.g., Swenson and Enquist 2007; Lamanna et al. 2014).

We conclude that suites of leaf and stem traits that reflect resource-use strategies concerning carbon, water, and nutrient are functionally coordinated, forming a single axis of trait variation in closely related species. This result supports the theory of a plant economics spectrum in an evolutionary context. We also suggest that temperature or associated growth-favorable period affect the strength of the coordination between leaf and stem traits under humid conditions. Future research is required to examine the observed relationships in different plant linages with different evolutionary histories. Such research will help to clarify how evolution constrains the trait correlation networks in leaves and stems.

\section{Acknowledgements}

Ashiu Forest Research Station, Wakayama Forest Research Station, Kiioshima Research Station, all of which belong to FSERC, Kyoto University, Ashoro Research Forest, Kasuya Research Forest, Kyushu University, Yona Field, University of the Ryukyus, Sakaerat Environmental Research Station, and land owners of Mt. Oeyama allowed and assisted us to collect samples. Lourens Poorter and one anonymous reviewer provided valuable suggestions to improve the manuscript. Y. Onoda allowed us to use the device for the punch test. Carbon isotope analysis was conducted using Cooperative Research Facilities (Isotope Ratio Mass Spectrometer) of the Center for Ecological Research, Kyoto University. This research was funded by Grant-in-Aid for JSPS Research Fellow to K.K. (17J05458).

\section{References}

Aguilar-Romero, R., Pineda-Garcia, F., Paz, H., González-Rodríguez, A., and Oyama, K. 2017. Differentiation in the water-use strategies among oak species from central Mexico. Tree Physiol. 37(7): 915-925. doi:10.1093/treephys/tpx033. 
Aiba, M., Kurokawa, H., Onoda, Y., Oguro, M., Nakashizuka, T., and Masaki, T. 2016. Context-dependent changes in the functional composition of tree communities along successional gradients after land-use change. J. Ecol. 104(5): 1347-1356. doi:10.1111/1365-2745.12597.

Baraloto, C., Paine, C.E.T., Poorter, L., Beauchene, J., Bonal, D., Domenach, A.M., Hérault, B., Patiño, S., Roggy, J.C., and Chave, J. 2010. Decoupled leaf and stem economics in rain forest trees. Ecol. Lett. 13(11): 1338-1347. doi:10.1111/j.1461-0248.2010.01517.x.

Boyce, C.K., Brodribb, T.J., Feild, T.S., and Zwieniecki, M.A. 2009. Angiosperm leaf vein evolution was physiologically and environmentally transformative. Proc. R. Soc. Lond. B Biol. Sci. 276(1663): 17711776. doi:10.1098/rspb.2008.1919.

Brodribb, T.J., and Feild, T.S. 2000. Stem hydraulic supply is linked to leaf photosynthetic capacity: evidence from New Caledonian and Tasmanian rainforests. Plant Cell Environ. 23(12): 1381-1388. doi:10.1046/j.1365-3040.2000.00647.x.

Brodribb, T.J., Feild, T.S., and Jordan, G.J. 2007. Leaf maximum photosynthetic rate and venation are linked by hydraulics. Plant Physiol. 144(4): 1890-1898. doi:10.1104/pp.107.101352.

Brodribb, T.J., Jordan, G.J., and Carpenter, R.J. 2013. Unified changes in cell size permit coordinated leaf evolution. New Phytol. 199(2): 559-570. doi:10.1111/nph.12300.

Cavender-Bares, J., Kitajima, K., and Bazzaz, F.A. 2004. Multiple trait associations in relation to habitat differentiation among 17 Floridian oak species. Ecol. Monogr. 74(4): 635-662. doi:10.1890/03-4007.

Chave, J., Coomes, D., Jansen, S., Lewis, S.L., Swenson, N.G., and Zanne, A.E. 2009. Towards a worldwide wood economics spectrum. Ecol. Lett. 12(4): 351-366. doi:10.1111/j.1461-0248.2009.01285.x.

Choat, B., Cobb, A.R., and Jansen, S. 2008. Structure and function of bordered pits: new discoveries and impacts on whole-plant hydraulic function. New Phytol. 177(3): 608-626. doi:10.1111/j.14698137.2007.02317.x.

Cornwell, W.K., and Ackerly, D.D. 2009. Community assembly and shifts in plant trait distributions across an environmental gradient in coastal California. Ecol. Monogr. 79(1): 109-126. doi:10.1890/07-1134.1.

Díaz, S., Hodgson, J.G., Thompson, K., Cabido, M., Cornelissen, J.H.C., Jalili, A., Montserrat-Martí, G., Grime, J.P., Zarrinkamar, F., Asri, Y., Band, S.R., Basconcelo, S., Castro-Díez, P., Funes, G., Hamzehee, B., Khoshnevi, M., Pérez-Harguindeguy, N., Pérez-Rontomé, M.C., Shirvanym, F.A., Vendramini, F., Yazdani, S., Abbas-Azimi, R., Bogaard, A., Boustani, S., Charles, M., Dehghan, M., de Torres-Espuny, L., Falczuk, V., Guerrero-Campo, J., Hynd, A., Jones, G., Kowsary, E., Kazemi-Saeed, F., MaestroMartínez, M., Romo-Díez, A., Shaw, S., Siavash, B., Villar-Salvador, P., and Zak, M.R. 2004. The plant 
traits that drive ecosystems: Evidence from three continents. J. Veg. Sci. 15(3): 295-304. doi:10.1111/j.1654-1103.2004.tb02266.x.

Díaz, S., Kattge, J., Cornelissen, J.H.C., Wright, I.J., Lavorel, S., Dray, S., Reu, B., Kleyer, M., Wirth, C., Prentice, I.C., Garnier, E., Bönisch, G., Westoby, M., Poorter, H., Reich, P.B., Moles, A.T., Dickie, J., Gillison, A.N., Zanne, A.E., Chave, J., Wright, S.J., Sheremet'ev, S.N., Jactel, H., Christopher, B., Cerabolini, B., Pierce, S., Shipley, B., Kirkup, D., Casanoves, F., Joswig, J.S., Günther, A., Falczuk, V., Rüger, N., Mahecha, M.D., and Gorné, L.D. 2015. The global spectrum of plant form and function. Nature, 529(7585): 167-171. doi:10.1038/nature16489.

Fan, Z.X., Zhang, S.B., Hao, G.Y., Ferry Slik, J.W., and Cao, K.F. 2012. Hydraulic conductivity traits predict growth rates and adult stature of 40 Asian tropical tree species better than wood density. J. Ecol. 100(3): 732-741. doi:10.1111/j.1365-2745.2011.01939.x.

Farquhar, G.D., Ehleringer, J.R., and Hubick, K.T. 1989. Carbon isotope discrimination and photosynthesis. Annu. Rev. Plant Physiol. Plant Mol. Biol. 40: 503-537. doi:10.1146/annurev.pp.40.060189.002443.

Franks, P.J., and Farquhar, G.D. 2001. The effect of exogenous abscisic acid on stomatal development, stomatal mechanics, and leaf gas exchange in Tradescantia virginiana. Plant Physiol. 125(2): 935-942. doi:10.1104/pp.125.2.935.

Freschet, G.T., Cornelissen, J.H.C., van Logtestijn, R.S.P., and Aerts, R. 2010. Evidence of the 'plant economics spectrum' in a subarctic flora. J. Ecol. 98(2): 362-373. doi:10.1111/j.1365-2745.2009.01615.x.

Funk, J.L., and Cornwell, W.K. 2013. Leaf traits within communities: context may affect the mapping of traits to function. Ecology, 94(9): 1893-1897. doi:10.1890/12-1602.1.

Griffin-Nolan, R.J., Bushey, J.A., Carroll, C.J.W., Challis, A., Chieppa, J., Garbowski, M., Hoffman, A.M., Post, A.K., Slette, I.J., Spitzer, D., Zambonini, D., Ocheltree, T.W., Tissue, D.T., and Knapp, A.K. 2018. Trait selection and community weighting are key to understanding ecosystem responses to changing precipitation regimes. Funct. Ecol. 32: 1746-1756. doi:10.1111/1365-2435.13135.

Grime, J.P., Thompson, K., Hunt, R., Hodgson, J.G., Cornelissen, J.H.C., Rorison, I.H., Hendry, G.A.F., Ashenden, T.W., Askew, A.P., Band, S.R., Booth, R.E., Bossard, C.C., Campbell, B.D., Cooper, J.E.L., Davison, A.W., Gupta, P.L., Hall, W., Hand, D.W., Hannah, M.A., Hillier, S.H., Hodkinson, D.J., Jalili, A., Liu, Z., Mackey, J.M.L., Matthews, N., Mowforth, M.A., Neal, A.M., Reader, R.J., Reiling, K., RossFraser, W., Spencer, R.E., Sutton, F., Tasker, D.E., Thorpe, P.C., and Whitehouse, J. 1997. Integrated screening validates primary axes of specialisation in plants. Oikos, 79(2): 259-281. doi:10.2307/3546011. 
Hacke, U.G., Sperry, J.S., Pockman, W.T., Davis, S.D., and McCulloh, K.A. 2001. Trends in wood density and structure are linked to prevention of xylem implosion by negative pressure. Oecologia, 126(4): 457-461. doi:10.1007/s004420100628.

Heberling, J.M., and Fridley, J.D. 2012. Biogeographic constraints on the world-wide leaf economics spectrum. Glob. Ecol. Biogeogr. 21(12): 1137-1146. doi:10.1111/j.1466-8238.2012.00761.x.

Ishida, A., Nakano, T., Yazaki, K., Matsuki, S., Koike, N., Lauenstein, D.L., Shimizu, M., and Yamashita, N. 2008. Coordination between leaf and stem traits related to leaf carbon gain and hydraulics across 32 drought-tolerant angiosperms. Oecologia, 156(1): 193-202. doi:10.1007/s00442-008-0965-6.

Jacobsen, A.L., Ewers, F.W., Pratt, R.B., Paddock III, W.A., and Davis, S.D. 2005. Do xylem fibers affect vessel cavitation resistance? Plant Physiol. 139(1): 546-556. doi:10.1104/pp.104.058404.

John, G.P., Scoffoni, C., and Sack, L. 2013. Allometry of cells and tissues within leaves. Am. J. Bot. 100(10): 1936-1948. doi:10.3732/ajb.1200608.

Kamiya, K., Harada, K., Ogino, K., Clyde, M.M., and Latiff, A.M. 2003. Phylogeny and genetic variation of Fagaceae in tropical montane forests. Tropics, 2: 119-125. doi:http://dx.doi.org/10.3759/tropics.13.119. Kawai, K., and Okada, N. 2016. How are leaf mechanical properties and water-use traits coordinated by vein traits? A case study in Fagaceae. Funct. Ecol. 30(4): 527-536. doi:10.1111/1365-2435.12526.

Kikuzawa, K., Onoda, Y., Wright, I.J., and Reich, P.B. 2013. Mechanisms underlying global temperaturerelated patterns in leaf longevity. Glob. Ecol. Biogeogr. 22(8): 982-993. doi:10.1111/geb.12042.

Kira, T. 1977. A climatological interpretation of Japanese vegetation zones. In Vegetation Science and Environmental Protection. Edited by A. Miyawaki and R. Tüxen. Maruzen, Tokyo, Japan. pp. 21-30.

Kitajima, K., Cordero, R.A., and Wright, S.J. 2013. Leaf life span spectrum of tropical woody seedlings: effects of light and ontogeny and consequences for survival. Ann. Bot. 112(4): 685-699. doi:10.1093/aob/mct036.

Kitajima, K., Llorens, A.M., Stefanescu, C., Timchenko, M.V., Lucas, P.W., and Wright, S.J. 2012. How cellulose-based leaf toughness and lamina density contribute to long leaf lifespans of shade-tolerant species. New Phytol. 195(3): 640-652. doi:10.1111/j.1469-8137.2012.04203.x.

Kubota, Y., Hirao, T., Fujii, S., Shiono, T., and Kusumoto, B. 2014. Beta diversity of woody plants in the Japanese archipelago: the roles of geohistorical and ecological processes. J. Biogeogr. 41(7): 1267-1276. doi:10.1111/jbi.12290.

de la Riva, E.G., Tosto, A., Pérez-Ramos, I.M., Navarro-Fernández, C.M., Olmo, M., Anten, N.P.R., Marañón, T., and Villar, R. 2016. A plant economics spectrum in Mediterranean forests along environmental 
gradients: is there coordination among leaf, stem and root traits? J. Veg. Sci. 27(1): 187-199. doi:10.1111/jvs.12341.

Lamanna, C., Blonder, B., Violle, C., Kraft, N.J.B., Sandel, B., Šímová, I., Donoghue, J.C., Svenning, J.C., McGill, B.J., Boyle, B., Buzzard, V., Dolins, S., Jørgensen, P.M., Marcuse-Kubitza, A., Morueta-Holme, N., Peet, R.K., Piel, W.H., Regetz, J., Schildhauer, M., Spencer, N., Thiers, B., Wiser, S.K., and Enquist, B.J. 2014. Functional trait space and the latitudinal diversity gradient. Proc. Natl. Acad. Sci. U.S.A. 111(38): 13745-13750. doi:10.1073/pnas.1317722111.

Manos, P.S., and Stanford, A.M. 2001. The historical biogeography of Fagaceae: tracking the tertiary history of temperate and subtropical forests of the northern hemisphere. Int. J. Plant Sci. 162(S6): S77-S93. doi: $10.1086 / 323280$.

Markesteijn, L., Poorter, L., Bongers, F., Paz, H., and Sack, L. 2011. Hydraulics and life history of tropical dry forest tree species: coordination of species' drought and shade tolerance. New Phytol. 191(2): 480-495. doi:10.1111/j.1469-8137.2011.03708.x.

McGill, B.J., Enquist, B.J., Weiher, E., and Westoby, M. 2006. Rebuilding community ecology from functional traits. Trends Ecol. Evol. 21(4): 178-185. doi:10.1016/j.tree.2006.02.002.

Meinzer, F.C., Campanello, P.I., Domec, J.C., Gatti, M.G., Goldstein, G., Villalobos-Vega, R., and Woodruff, D.R. 2008. Constraints on physiological function associated with branch architecture and wood density in tropical forest trees. Tree Physiol. 28(11): 1609-1617. doi:10.1093/treephys/28.11.1609.

Méndez-Alonzo, R., Paz, H., Cruz, R., Rosell, J.A., and Olson, M.E. 2012. Coordinated evolution of leaf and stem economics in tropical dry forest trees. Ecology, 93(11): 2397-2406. doi:10.2307/41739311.

Olson, M.E., Anfodillo, T., Rosell, J.A., Petit, G., Crivellaro, A., Isnard, S., León-Gómez, C., AlvaradoCárdenas, L.O., and Castorena, M. 2014. Universal hydraulics of the flowering plants: vessel diameter scales with stem length across angiosperm lineages, habits and climates. Ecol. Lett. 17(8): 988-997. doi:10.1111/ele.12302.

Pantin, F., Simonneau, T., and Muller, B. 2012. Coming of leaf age: control of growth by hydraulics and metabolics during leaf ontogeny. New Phytol. 196(2): 349-366. doi:10.1111/j.1469-8137.2012.04273.x.

Poorter, L., and Bongers, F. 2006. Leaf traits are good predictors of plant performance across 53 rain forest species. Ecology, 87(7): 1733-1743. doi:10.1890/0012-9658(2006)87[1733:LTAGPO]2.0.CO;2.

Poorter, L., McDonald, I., Alarcón, A., Fichtler, E., Licona, J.C., Peña-Claros, M., Sterck, F., Villegas, Z., and Sass-Klaassen, U. 2010. The importance of wood traits and hydraulic conductance for the performance and life history strategies of 42 rainforest tree species. New Phytol. 185(2): 481-492. doi:10.1111/j.14698137.2009.03092.x. 
Preston, K.A., Cornwell, W.K., and Denoyer, J.L. 2006. Wood density and vessel traits as distinct correlates of ecological strategy in 51 California coast range angiosperms. New Phytol. 170(4): 807-818. doi:10.1111/j.1469-8137.2006.01712.x.

R core team. 2016. R: A language and environment for statistical computing. R Foundation for Statistical Computing. Vienna, Austria.

Reich, P.B. 2014. The world-wide "fast-slow" plant economics spectrum: a traits manifesto. J. Ecol. 102(2): 275-301. doi:10.1111/1365-2745.12211.

Sack, L., Cowan, P.D., Jaikumar, N., and Holbrook, N.M. 2003. The 'hydrology' of leaves: co-ordination of structure and function in temperate woody species. Plant Cell Environ. 26(8): 1343-1356. doi:10.1046/j.0016-8025.2003.01058.x.

Sack, L., Scoffoni, C., John, G.P., Poorter, H., Mason, C.M., Mendez-Alonzo, R., and Donovan, L.A. 2013. How do leaf veins influence the worldwide leaf economic spectrum? Review and synthesis. J. Exp. Bot. 64(13): 4053-4080. doi:10.1093/jxb/ert316.

Santiago, L.S., Goldstein, G., Meinzer, F.C., Fisher, J.B., Machado, K., Woodruff, D., and Jones, T. 2004. Leaf photosynthetic traits scale with hydraulic conductivity and wood density in Panamanian forest canopy trees. Oecologia, 140(4): 543-550. doi:10.1007/s00442-004-1624-1.

Schindelin, J., Arganda-Carreras, I., Frise, E., Kaynig, V., Longair, M., Pietzsch, T., Preibisch, S., Rueden, C., Saalfeld, S., Schmid, B., Tinevez, J.Y., White, D.J., Hartenstein, V., Eliceiri, K., Tomancak, P., and Cardona, A. 2012. Fiji: an open-source platform for biological-image analysis. Nat. Methods, 9(7): 67682. doi:10.1038/nmeth.2019.

Scoffoni, C., Chatelet, D.S., Pasquet-Kok, J., Rawls, M., Donoghue, M.J., Edwards, E.J., and Sack, L. 2016. Hydraulic basis for the evolution of photosynthetic productivity. Nat. Plants, 2: 16072. doi:10.1038/nplants.2016.72.

Sterck, F., Markesteijn, L., Schieving, F., and Poorter, L. 2011. Functional traits determine trade-offs and niches in a tropical forest community. Proc. Natl. Acad. Sci. U.S.A. 108(51): 20627-20632. doi:10.1073/pnas.1106950108.

Swenson, N.G., and Enquist, B.J. 2007. Ecological and evolutionary determinants of a key plant functional trait: wood density and its community-wide variation across latitude and elevation. Am. J. Bot. 94(3): 451-459. doi:10.3732/ajb.94.3.451.

Tyree, M.T., and Zimmermann, M.H. 2002. Xylem structure and the ascent of sap. Springer Berlin Heidelberg. 
Villar, R., Poorter, L., Wright, I.J., Niinemets, Ü., and Poorter, H. 2009. Causes and consequences of variation in leaf mass per area (LMA): a meta-analysis. New Phytol. 182(3): 565-588. doi:10.1111/j.14698137.2009.02830.x.

Violle, C., Navas, M.L., Vile, D., Kazakou, E., Fortunel, C., Hummel, I., and Garnier, E. 2007. Let the concept of trait be functional! Oikos, 116(5): 882-892. doi:10.1111/j.2007.0030-1299.15559.x.

Weiher, E., and Keddy, P.A. 1995. Assembly rules, null models, and trait dispersion: new questions from old patterns. Oikos, 74(1): 159-164. doi:10.2307/3545686.

Westbrook, J.W., Kitajima, K., Burleigh, J.G., Kress, W.J., Erickson, D.L., and Wright, S.J. 2011. What makes a leaf tough? patterns of correlated evolution between leaf toughness traits and demographic rates among 197 shade-tolerant woody species in a neotropical Forest. Am. Nat. 177(6): 800-811. doi:10.1086/659963.

Wheeler, J.K., Sperry, J.S., Hacke, U.G., and Hoang, N. 2005. Inter-vessel pitting and cavitation in woody Rosaceae and other vessel led plants: a basis for a safety versus efficiency trade-off in xylem transport. Plant Cell Environ. 28(6): 800-812. doi:10.1111/j.1365-3040.2005.01330.x.

Wright, I.J., Reich, P.B., Cornelissen, J.H.C., Falster, D.S., Groom, P.K., Hikosaka, K., Lee ,W., Lusk, C.H., Niinemets, Ü., Oleksyn, J., Osada, N., Poorter, H., Warton, D.I., and Westoby, M. 2005. Modulation of leaf economic traits and trait relationships by climate. Glob. Ecol. Biogeogr. 14(5): 411-421. doi:10.1111/j.1466-822x.2005.00172.x.

Wright, I.J., Reich, P.B., Westoby, M., Ackerly, D.D., Baruch, Z., Bongers, F., Cavender-Bares, J., Chapin, T., Cornellssen, J.H.C., Diemer, M., Flexas, J., Garnier, E., Groom, P.K., Gulias, J., Hikosaka, K., Lamont, B.B., Lee, T., Lee, W., Lusk, C., Midgley, J.J., Navas, M.L., Niinemets, Ü., Oleksyn, J., Osada, H., Poorter, H., Pool, P., Prior, L., Pyankov, V.I., Roumet, C., Thomas, S.C., Tjoelker, M.G., Veneklaas, E.J., and Villar, R. 2004. The worldwide leaf economics spectrum. Nature, 428(6985): 821-827. doi:10.1038/nature02403.

Wright, S.J., Kitajima, K., Kraft, N.J.B., Reich, P.B., Wright, I.J., Bunker, D.E., Condit, R., Dalling, J.W., Davies, S.J., Díaz S, Engelbrecht, B.M.J., Harms, K.E., Hubbell, S.P., Marks, C.O., Ruiz-Jaen, M.C., Salvador, C.M., and Zanne, A.E. 2010. Functional traits and the growth-mortality trade-off in tropical trees. Ecology, 91(12): 3664-3674. doi:10.1890/09-2335.1.

Zhang, J.L., and Cao, K.F. 2009. Stem hydraulics mediates leaf water status, carbon gain, nutrient use efficiencies and plant growth rates across dipterocarp species. Funct. Ecol. 23(4): 658-667. doi:10.1111/j.1365-2435.2009.01552.x. 
Table 1. The 25 Fagaceae species studied, species code, and biomes

\begin{tabular}{|c|c|c|}
\hline Species & Code & Biome \\
\hline Castanea crenata Siebold et Zucc. & Cer & CTM-WTM \\
\hline Castanopsis piriformis Hickel \& A.Camus & Cpi & TROP \\
\hline Castanopsis sieboldii (Makino) Hatus. ex T.Yamaz. et Mashiba & Csi & WTM-TROP \\
\hline Fagus crenata Blume & For & СТM \\
\hline Fagus japonica Maxim. & Fja & СТM \\
\hline Lithocarpus edulis (Makino) Nakai & Led & WTM-TROP \\
\hline Lithocarpus glaber (Thunb.) Nakai & Lgl & WTM \\
\hline Lithocarpus sp1 & Ls1 & TROP \\
\hline Lithocarpus sp2 & Ls2 & TROP \\
\hline Lithocarpus sp3 & Ls3 & TROP \\
\hline Quercus acuta Thunb. & Qac & CTM-WTM \\
\hline Quercus aliena Blume & Qal & WTM \\
\hline Quercus crispula Blume & Qcr & СТм \\
\hline Quercus dentata Thunb. & Qde & СТМ \\
\hline Quercus gilva Blume & Qgi & WTM \\
\hline Quercus glauca Thunb. & Qgl & WTM \\
\hline Quercus hondae Makino & Qho & WTM \\
\hline Quercus kerrii Craib & Qke & TROP \\
\hline Quercus miyagii Koidz. & Qmi & TROP \\
\hline Quercus myrsinifolia Blume & Qmy & WTM \\
\hline Quercus phillyreoides A.Gray & Qph & WTM \\
\hline Quercus salicina Blume & Qsa & CTM-WTM \\
\hline Quercus serrata Murray & Qse & CTM-WTM \\
\hline Quercus sessilifolia Blume & Qss & CTM-WTM \\
\hline Quercus variabilis Blume & Qva & СТM \\
\hline
\end{tabular}

$\mathrm{CTM}=$ cool temperate forest, $\mathrm{CTM}-\mathrm{WTM}=\mathrm{cool}$ and warm temperate forest, $\mathrm{WTM}=$ warm temperate forest, $\mathrm{WTM}-\mathrm{TROP}=$ warm temperate and tropical forest, TROP $=$ tropical forest. 
Table 2. Leaf and stem traits studied in this study, including minimum species mean, the mean species of means, the maximum species mean of 25 Fagaceae, groups of traits, correlation ( $r$ ) with the global PCA Axes 1 and 2 and their ecological significance

\begin{tabular}{|c|c|c|c|c|c|c|c|c|c|}
\hline Trait & Symbol & Unit & Mean & Min & Max & Group & $r$ with $\mathrm{PC} 1$ & $r$ with $\mathrm{PC} 2$ & Ecological significance \\
\hline Force to punch per unit perimeter of fracture & $F_{\mathrm{p}}$ & $\mathrm{kN} \mathrm{m}^{-1}$ & 1.39 & 0.61 & 2.48 & Leaf & $0.86^{* * *}$ & ns & Defense from abiotic and biotic stress \\
\hline Specific force to punch & $F_{\mathrm{ps}}$ & $\mathrm{MN} \mathrm{m}^{-2}$ & 5.88 & 3.42 & 8.03 & Leaf & $0.75 * * *$ & ns & Defense from abiotic and biotic stress \\
\hline Density-corrected specific force to punch ${ }^{a}$ & $F_{\mathrm{TD}}$ & $\mathrm{N} \mathrm{g}^{-1} \mathrm{~m}^{1}$ & 12.28 & 7.88 & 20.72 & Leaf & $0.65 * * *$ & ns & Defense from abiotic and biotic stress \\
\hline Potential maximum stomatal conductance to water vapor & $g_{\operatorname{smax}}$ & $\mathrm{mol} \mathrm{m}^{-2} \mathrm{~s}^{-1}$ & 1.74 & 0.81 & 3.23 & Leaf & $-0.65 * * *$ & $-0.57 * *$ & Gas exchange capacity \\
\hline Stomatal density & SD & $\mathrm{mm}^{-2}$ & 544 & 195 & 828 & Leaf & $-0.60 * *$ & ns & Gas exchange capacity \\
\hline Minor vein density & $\mathrm{VLA}_{\min }$ & $\mathrm{mm} \mathrm{mm}^{-2}$ & 10.8 & 7.7 & 15.20 & Leaf & $-0.52 * *$ & ns & Water transport capacity in leaf \\
\hline Minor vein thickness & VT & $\mathrm{mm}$ & 0.03 & 0.02 & 0.04 & Leaf & $0.71 * * *$ & ns & Vein construction cost \\
\hline Minor vein volume per unit area & VVA & $\mathrm{mm}^{3} \mathrm{~cm}^{-2}$ & 0.92 & 0.56 & 1.39 & Leaf & $0.41 *$ & ns & Vein construction cost \\
\hline Stable carbon isotope ratio & $\delta^{13} \mathrm{C}$ & $\%$ & -30.0 & -32.1 & -27.4 & Leaf & ns & $-0.47 *$ & Long term water use efficiency \\
\hline Dry-mass based leaf nitrogen concentration & $N_{\text {mass }}$ & $\%$ & 1.60 & 1.20 & 2.11 & Leaf & $-0.52 * *$ & ns & Photosynthetic capacity \\
\hline Area-based leaf nitrogen concentration & $N_{\text {arca }}$ & $\mathrm{g} \mathrm{m}^{-2}$ & 1.78 & 0.96 & 2.65 & Leaf & $0.44 *$ & $-0.69 * * *$ & Photosynthetic capacity \\
\hline Lamina thickness & LT & $\mathrm{mm}$ & 0.23 & 0.11 & 0.38 & Leaf & $0.68 * * *$ & $-0.61 * *$ & Photosynthetic capacity \\
\hline Lamina tissue density & TD & $\mathrm{g} \mathrm{cm}^{-3}$ & 0.49 & 0.39 & 0.57 & Leaf & ns & ns & $\begin{array}{l}\text { Photosynthetic capacity, drought tolerance, } \\
\text { Defense from abiotic and biotic stress }\end{array}$ \\
\hline Leaf area ${ }^{a}$ & LA & $\mathrm{cm}^{2}$ & 34.8 & 5.05 & 145.6 & Leaf & $-0.56 * *$ & ns & Light capture \\
\hline Leaf dry mass per area & LMA & $\mathrm{g} \mathrm{m}^{-2}$ & 114 & 58 & 181 & Leaf & $0.68 * * *$ & $-0.58 * *$ & Photosynthetic capacity, leaf longevity \\
\hline Wood density & wD & $\mathrm{g} \mathrm{cm}^{-3}$ & 0.69 & 0.50 & 0.85 & Stem & $0.45 *$ & ns & Defense from abiotic and biotic stress, resistance to cavitation \\
\hline Vessel density & VD & $\mathrm{mm}^{-2}$ & 16.4 & 2.1 & 158.5 & Stem & ns & $0.81 * * *$ & Water transport capacity \\
\hline Mean hydraulically weighted vessel diameter & $D_{\mathrm{h}}$ & $\mathrm{mm}$ & 0.16 & 0.04 & 0.30 & Stem & $-0.68 * * *$ & $-0.67 * * *$ & Water transport capacity \\
\hline Potential hydraulic conductivity & $K_{\mathrm{h}}$ & $\mathrm{kg} \mathrm{m}^{-1} \mathrm{MPa}^{-1} \mathrm{~s}^{-1}$ & 216 & 15.2 & 1191 & Stem & $-0.81 * * *$ & $-0.40 *$ & Water transport capacity \\
\hline
\end{tabular}

${ }^{a} \log _{10}$-transformed before analysis. For each species' trait data, see Table S2.

$* P<0.05, * * P<0.01, * * * P<0.001$, ns not significant 
Table 3. Pairwise relationships among 19 leaf and stem traits in 25 Fagaceae

\begin{tabular}{|c|c|c|c|c|c|c|c|c|c|c|c|c|c|c|c|c|c|c|c|}
\hline & & \multicolumn{15}{|l|}{ Leaf traits } & \multicolumn{3}{|l|}{ Stem traits } \\
\hline & & $F_{\mathrm{p}}$ & $F_{\mathrm{ps}}$ & $F_{\mathrm{TD}^{a}}{ }^{a}$ & $g_{\operatorname{smax}}$ & SD & $\mathrm{VLA}_{\min }$ & VT & VVA & $8^{13} \mathrm{C}$ & $N_{\text {mass }}$ & $N_{\text {area }}$ & LT & TD & $\mathrm{LA}^{a}$ & LMA & $\begin{array}{l}\text { WD } \\
\end{array}$ & VD & $\frac{D_{\mathrm{h}}}{4}$ \\
\hline \multirow[t]{14}{*}{ Leaf traits } & $F_{\mathrm{ps}}$ & $0.69 * * *$ & & & & & & & & & & & & & & & & & \\
\hline & $F_{\mathrm{TD}}{ }^{a}$ & $0.64 * * * *$ & $0.93 * * *$ & & & & & & & & & & & & & & & & \\
\hline & $g_{\max }$ & -0.29 & -0.40 & -0.26 & & & & & & & & & & & & & & & \\
\hline & SD & -0.44 * & -0.47 * & -0.47 * & $0.68 * * *$ & & & & & & & & & & & & & & \\
\hline & $V L A_{\min }$ & -0.50 * & $-0.46 *$ & -0.44 * & 0.41 * & 0.47 * & & & & & & & & & & & & & \\
\hline & VT & $0.65 * * * *$ & $0.50 *$ & 0.51 ** & -0.32 & $-0.42 *$ & -0.44 * & & & & & & & & & & & & \\
\hline & VVA & 0.37 & 0.22 & 0.25 & -0.07 & -0.14 & 0.15 & $0.82 * * * *$ & & & & & & & & & & & \\
\hline & $\delta^{13} \mathrm{C}$ & -0.04 & -0.22 & -0.25 & 0.41 * & 0.39 & 0.17 & -0.02 & 0.15 & & & & & & & & & & \\
\hline & $N_{\text {mass }}$ & -0.37 & -0.03 & 0.05 & 0.42 * & 0.10 & 0.14 & -0.36 & -0.30 & 0.07 & & & & & & & & & \\
\hline & $N_{\text {area }}$ & $0.71 * * * *$ & 0.24 & 0.15 & 0.04 & -0.16 & -0.17 & 0.35 & 0.26 & 0.21 & 0.05 & & & & & & & & \\
\hline & LT & 0.88 **** & 0.28 & 0.27 & -0.14 & -0.28 & -0.32 & 0.58 ** & 0.41 * & 0.05 & -0.46 * & $0.79 * * * *$ & & & & & & & \\
\hline & $\mathrm{TD}$ & -0.07 & -0.09 & -0.44 * & -0.27 & 0.13 & 0.15 & -0.13 & -0.03 & 0.13 & -0.29 & 0.15 & -0.04 & & & & & & \\
\hline & $\mathrm{LA}^{a}$ & -0.28 & -0.29 & -0.12 & 0.60 *** & 0.3 & 0.07 & -0.23 & -0.17 & 0.26 & 0.39 & -0.16 & -0.25 & -0.46 * & & & & & \\
\hline & LMA & $0.83 * * * *$ & 0.24 & 0.12 & -0.2 & -0.24 & -0.27 & $0.54 * *$ & 0.40 * & 0.11 & $-0.52 * *$ & $0.81 * * *$ & $0.95 * * *$ & 0.26 & -0.37 & & & & \\
\hline \multirow[t]{4}{*}{ Stem traits } & WD & 0.37 & 0.41 * & 0.30 & -0.01 & 0.14 & -0.15 & 0.26 & 0.19 & 0.33 & -0.27 & 0.25 & 0.26 & 0.22 & -0.10 & 0.33 & & & \\
\hline & VD & -0.40 * & -0.01 & -0.03 & -0.33 & -0.30 & 0.29 & -0.29 & -0.17 & -0.22 & 0.13 & -0.51 ** & $-0.52 * *$ & 0.10 & -0.16 & -0.48 * & -0.41 * & & \\
\hline & $D_{\mathrm{h}}$ & -0.30 & $-0.53 * *$ & -0.43 * & $0.82 * * * *$ & 0.54 ** & 0.23 & -0.28 & -0.12 & 0.34 & 0.48 * & 0.18 & -0.09 & -0.19 & $0.64 * * * *$ & -0.13 & -0.16 & -0.47 * & \\
\hline & $K_{\mathrm{h}}$ & -0.47 * & -0.60 ** & $-0.51 * *$ & 0.76 **** & 0.52 ** & 0.28 & -0.43 * & -0.28 & 0.14 & 0.45 * & -0.06 & -0.27 & -0.13 & $0.61 * *$ & -0.30 & -0.37 & -0.16 & $0.85 * * *$ \\
\hline
\end{tabular}

The numbers shown are Pearson correlation coefficients. See trait abbreviations for Table 2. Significant correlations were shown in bold face.

${ }^{a} \log _{10}$-transformed before analysis.

* $P<0.05, * * P<0.01, * * * P<0.001$. 


\section{Figure captions}

Fig. 1 Relationships between (a) potential maximum stomatal conductance to water vapor $\left(g_{\text {smax }}\right)$ and potential hydraulic conductivity at stem $\left(K_{\mathrm{h}}\right)$ and $(\mathrm{b})$ between specific force to punch $\left(F_{\mathrm{ps}}\right)$ and stem wood density for 25 Fagaceae species in East Asia. The curve in (a) is a positive exponential function fitted to the data $(y=43.6+1.90 \exp (1.97 \mathrm{x}))$. The line in $(\mathrm{b})$ was fitted by standard major axis (SMA; $\mathrm{y}=0.16+0.09 \mathrm{x}) . * * * P<0.001 ; * P<0.05$

Fig. 2 Principle component analysis of 16 leaf traits (black) and five stem traits (gray) traits for (a) three biomes, (c) cool temperate forest, (e) warm temperate forest, and (g) tropical forests. Right column shows the relationships between species scores of PC1 in the individual PCAs which included either leaf or stem traits for (b) three biomes, (d) cool temperate forest, (f) warm temperate forest, and (h) tropical forests. Numbers in parentheses represent the percentage of variance explained by each axis. Please note that $\mathrm{x}$-axis in (e) and $\mathrm{y}$-axis in (c) were reversed to locate the same traits to a similar position. The number of Fagaceae examined was $25,10,14$, and 8 for three biomes, cool temperate forest, warm temperate forest, and tropical forests, respectively. Symbols in (b) represent species' climatic occurrence; $\mathrm{CTM}=$ cool temperate forest, $\mathrm{CTM}-\mathrm{WTM}=$ cool and warm temperate forest, $\mathrm{WTM}=$ warm temperate forest, $\mathrm{WTM}$-TROP $=$ warm temperate and tropical forest, TROP $=$ tropical forest. The lines in (b), (d), and (f) were fitted by standard major axis (SMA). *** $P<0.001$; ** $P<0.01$; ns not significant. For (d), exclusion of two outliers (two Fagus species), which showed high PC1 scores in the stem PCA increased in the significance of the relationship. See Table 2 and Table S2 for abbreviations of species and traits, respectively. See Figure S2 for the results of individual PCAs which included either leaf or stem trait. 


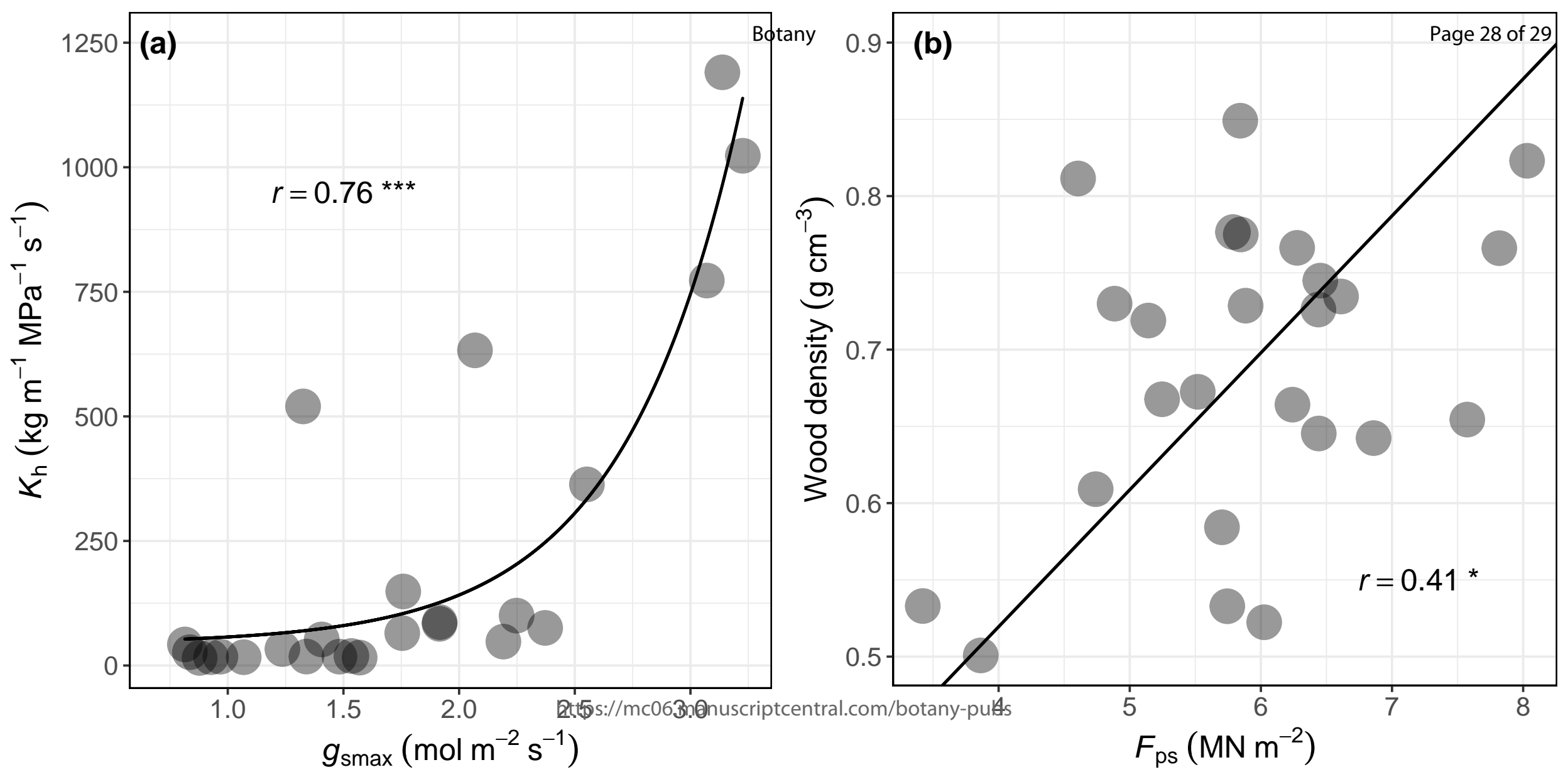



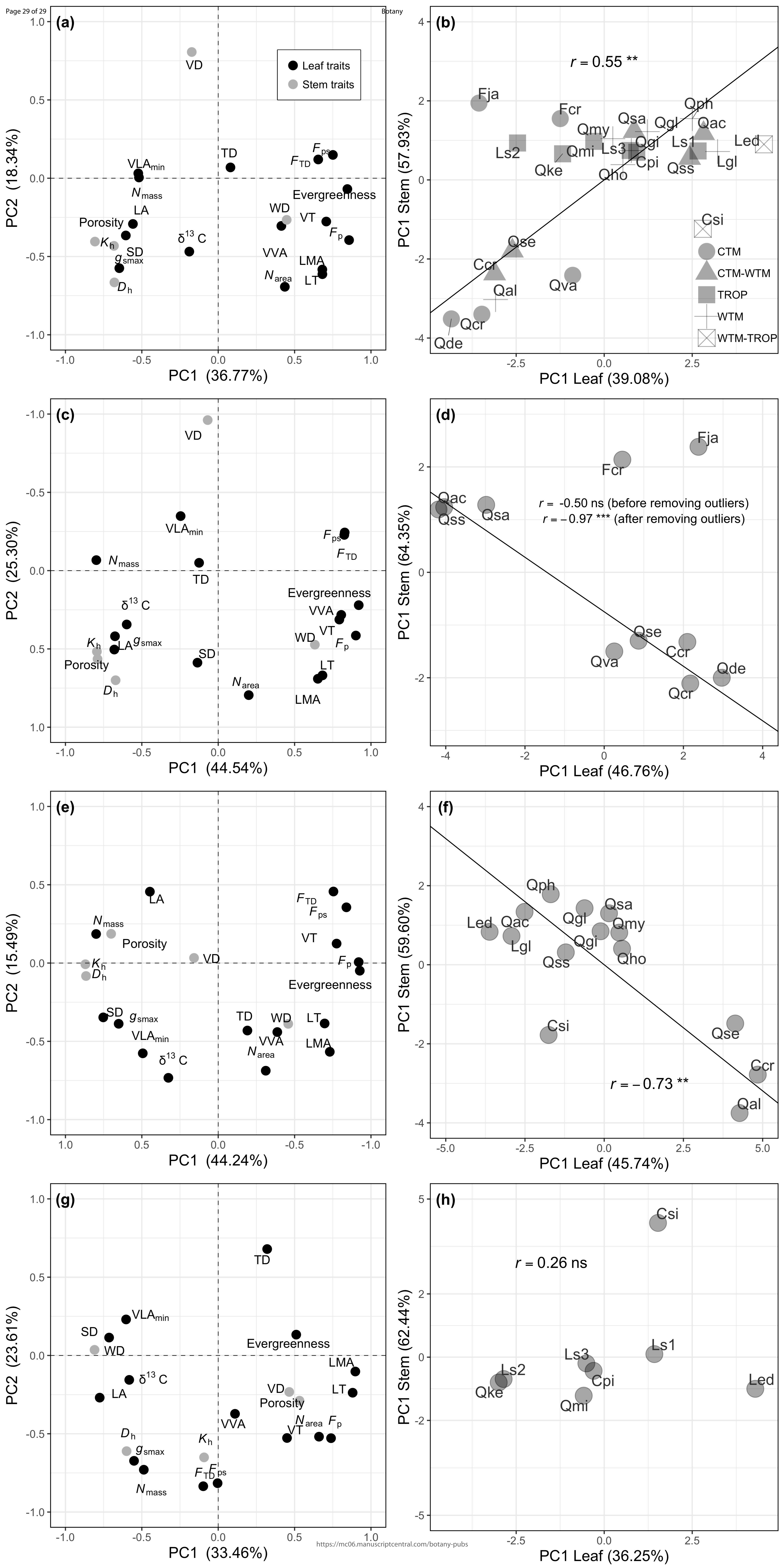